\title{
Load Cases Relevant for Proof of Competence of Fast Running Hoists
}

\author{
Stefan Vöth ${ }^{1, *}$ \\ ${ }^{1}$ Technische Hochschule Georg Agricola, Centre for Drive and Lifting Technology ZAFT, Bochum, \\ Germany
}

\begin{abstract}
Dynamically operated hoist systems are exposed to different load cases, which may induce high loads to the drivetrain. The paper shows the load cases and additional equipment, to restrict the loads out of these load cases to the hoist. Especially in focus are optional measures for the exceptional load cases emergency stop snag load. The load cases are listed including affiliated equipment and aspects to be considered during design phase.
\end{abstract}

\section{Technical Development}

Cranes in general and hoists especially comprise in transhipment of bulk or containers increasing operational speeds. A special example with regard to this are ship-to-shore container cranes. Today they cover lifting heights up to $72 \mathrm{~m}$ with lifting speeds of up to 180 $\mathrm{m} / \mathrm{min}$. Planned new ship generations even indicate possible further growth in crane and hoist performance.

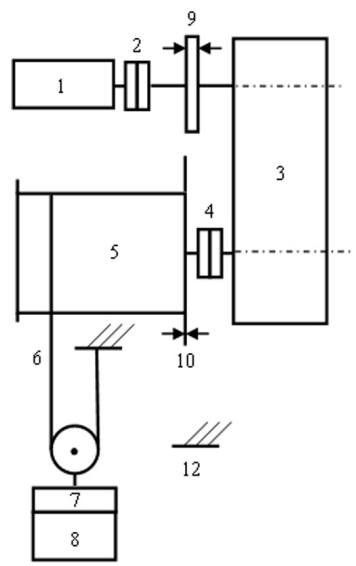

$$
\begin{aligned}
& \text { Motor } \\
& \text { Motor Coupling } \\
& \text { Gearing } \\
& \text { Drum Coupling } \\
& \text { Drum } \\
& \text { Rope Drive } \\
& \text { Load Attachment Device } \\
& \text { Load } \\
& \text { Service Brake } \\
& \text { Safety Brake } \\
& \text { Ground } \\
& \text { Environment }
\end{aligned}
$$

Fig. 1. Hoist Components.

\footnotetext{
*Corresponding author: stefan.voeth@thga.de
} 
Due to high operational speeds the lifting systems are on high levels of kinetic energy. This will affect system design in order to ensure safety for all operational situations, especially in situations in which the system has to be braked down. Safety comprises for example aspects as observance of intended operation, structural integrity [1], limited braking distances and availability of equipment. Relevant load cases may be correlated with the load case grouping according to [2]: Regular loads, non-regular loads and exceptional loads.

\section{Regular Loads}

Regular loads appear continuously during operation of the hoist. As they are no exceptional events, they have to be covered by fairly every hoist. Regular loads, neglecting deadweight, are acceleration and deceleration, pick up and drop off of load, slack rope, remaining rope windings and two blocking.

\subsection{Acceleration and deceleration}

Acceleration will occur at the beginning and the end of every hoist movement.

Acceleration processes typically are not supported by additional equipment to reduce loads to the hoist. Aspects to be considered: Preset motor accelerations, braking torques, dead times and regulative and contractual requirements.

\subsection{Pick up and drop off of load}

Pick up or drop off of load will occur during every working cycle of the crane.

Pick up or drop off processes typically are not supported by additional equipment to reduce loads to the hoist. Aspects to be considered: Hoisting speeds, lowering speeds, releasing characteristics of load attachment devices as magnets, grabs etc., releasing characteristics of load attachment devices as magnets during unintended release and regulative and contractual requirements. 

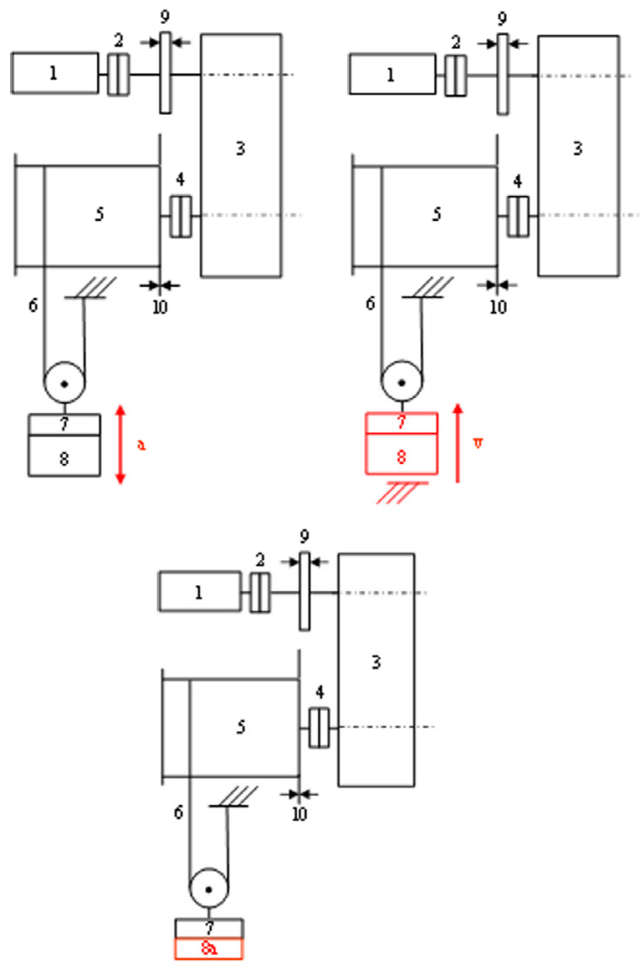

क

Fig. 2. Load cases acceleration/deceleration, Pick up of load and drop off of load.

\subsection{Slack Rope}

Slack rope will occur, when a lowering movement continues after putting a load to the ground. System design options:

Lower Limit Switch: With regard to the ground position too much slack rope may be prevented by a lower limit switch. It has to be considered, that this switch can only be adapted to the "lowest ground". If there are different ground levels, the upper levels are not covered by the switch. For these ground levels other strategies may be considered (alternative ground recognition system, slack rope tolerant hoisting system). Aspects to be considered: Operational lowering speeds, rope lengthening, variety of geometric load properties, infrastructural changes, regulative and contractual requirements.

Underload Switch Off: An option is the measurement of the load by a load measuring device and to initiate a braking procedure as soon as a load limit is exceeded. Depending on the load, the switching characteristics and the lifting speed a corresponding slack rope length has to be expected. Aspects to be considered: Relation of maximum lifting height, rope weight and hook block weight (maybe an exclusion condition), measuring frequency, data processing and triggering level, regulative and contractual requirements.

\subsection{Remaining Rope Windings}

Remaining rope windings on the rope drum have to be ensured, when during lowering operation no ground is reached. System design options: 
Lower Limit Switch: Remaining rope windings on the rope drum may be ensured by a lower limit switch at the hoist drivetrain. Aspects to be considered: Operational lowering speeds, regulative and contractual requirements.

\subsection{Two Blocking}

Two blocking will occur, when a lifting movement continues after reaching the highest theoretical position of the hook block. System design options:

Upper Limit Switches: A feasible method is the positioning of a limit switch to allow a switch off of the hoisting movement on time. Aspects to be considered: Operational hoisting speeds, regulative and contractual requirements.

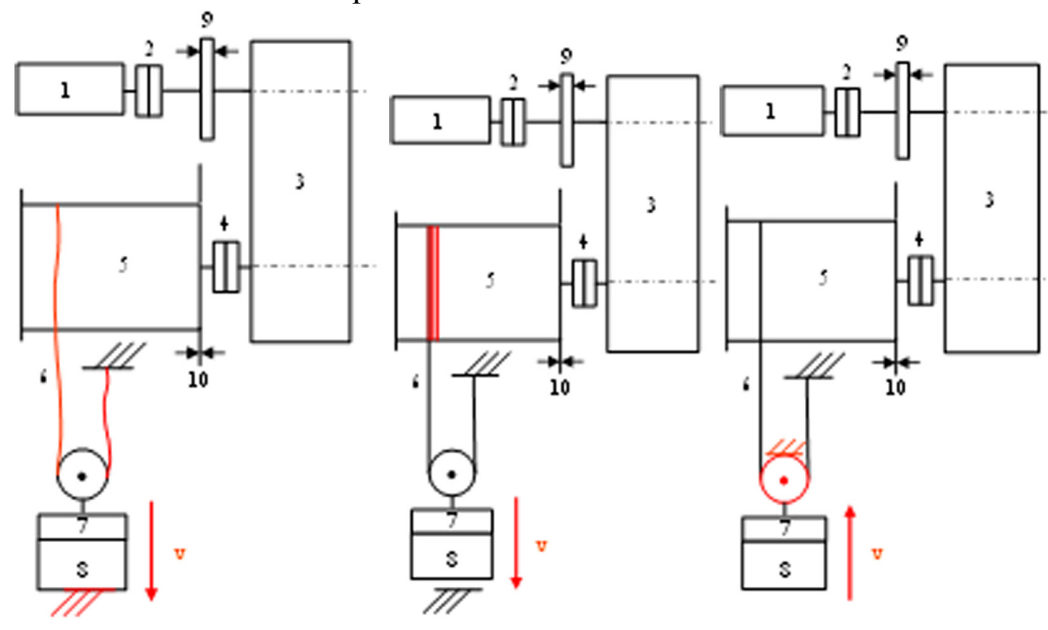

Fig. 3. Load cases slack rope, remaining rope windings, two blocking.

\section{Non Regular Loads}

Neglecting loads due to snow and ice non-regular loads according to [2] do not appear to hoists in drive direction.

\section{Exceptional Loads}

Exceptional loads are not planned to appear during operation of the hoist. Nevertheless they can be introduced by exceptional conditions. These exceptional conditions more or less most time have an accidental character. Exceptional loads may be special events which have to be covered only by certain hoists. Exceptional loads are overload, drivetrain failure, service brake failure, emergency stop and snag load. 

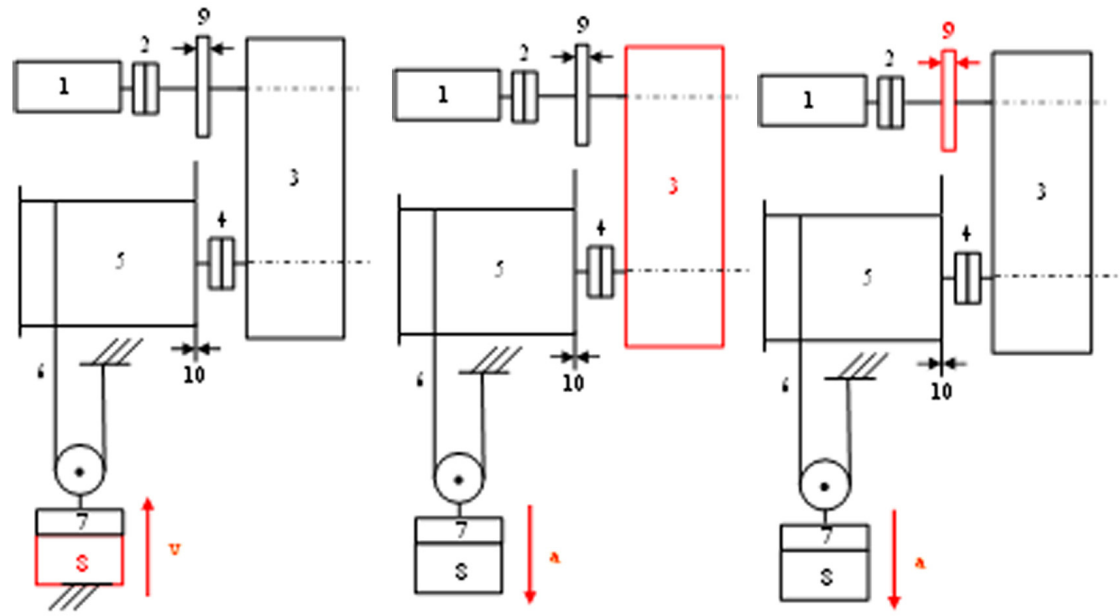

Fig. 4. Load cases overload, drivetrain failure, service brake failure.

\subsection{Overload}

Overload may happen, when the crane driver tries to lift a load greater than the rated capacity. System design options:

Overload Switch Off: An option is the measurement of the load by a load measuring device and to initiate a braking procedure as soon as a load limit is exceeded. Depending on the load, the switching characteristics and the lifting speed a corresponding maximum load to the system has to be expected. Aspects to be considered: Measuring accuracy, measuring frequency, data processing and triggering level, regulative and contractual requirements.

Frictional clutch: Another option is to locate a frictional clutch in the drivetrain. Depending on the switching torque a corresponding maximum load has to be expected. Aspects to be considered: Switching tolerance, regulative and contractual requirements.

\subsection{Drivetrain Failure}

Most probable drivetrain failure according to practice is a gearing failure. This failure may occur, when not permissible maximum torques are transferred via the gearing. System design options:

Angle Difference Sensor: The not any more given constant gearing ratio can be realized by a measurement of the input rotating angle and output rotating angle and the check of the relation of both to each other. The detected change in ratio gives the trigger for an automatic emergency stop [9]. Aspects to be considered: Triggering speed difference, brake lining speed, brake lining performance, regulative and contractual requirements.

Speed Sensor: An occurring overspeed of the load side can be realized by a speed sensing device. The detected overspeed gives the trigger for an automatic emergency stop $[9,10]$. Aspects to be considered: Triggering speed, brake lining speed, brake lining performance, regulative and contractual requirements.

\subsection{Service Brake Failure}

A conceivable failure may be a service brake failure. This failure may occur due to lining wear or misadjusting. System design options: 
Additional brake: A measure is to place an additional brake on the fast running motor axis. This additional brake may come into action parallel to the service brake. Optional the additional brake comes into action with a certain delay against the service brake $[10,11]$. Aspects to be considered: Total braking torque in case of simultaneous brake activity, triggering sequence of brakes, regulative and contractual requirements.
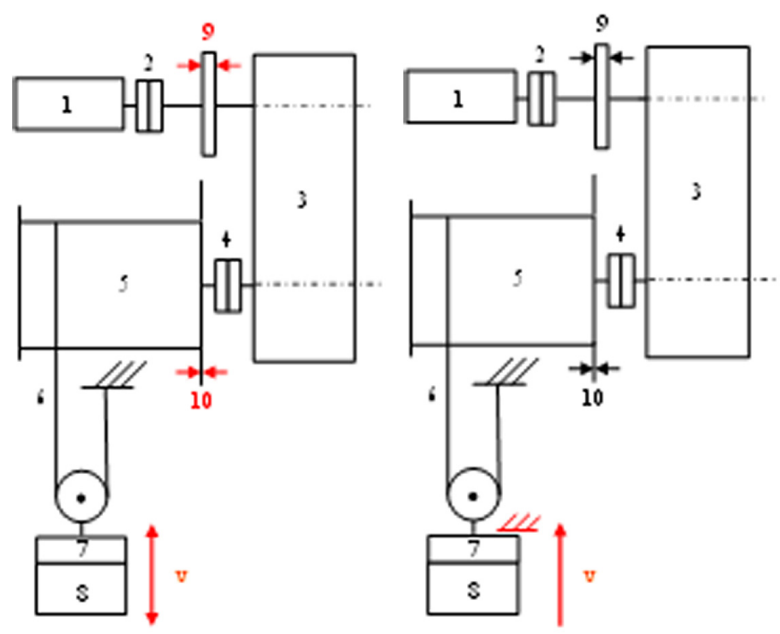

Fig. 5. Load cases emergency stop, snag.

\subsection{Emergency Stop}

A (manual) emergency stop will occur when introduced by the crane driver. Typically this is a result of a presumed critical operational condition. The following system behaviour depends on the position and the characteristics of the acting brake(s). Mechanical or electrical brakes acting on the fast running motor axis are of interest with regard to the braking distances, because they have to slow down the full rotational mass of the drivetrain. Mechanical brakes acting on the slow running drum axis are, beside the braking distances, of interest with regard to the drivetrain loading. Out of lifting operation about the sum of load torque and braking torque has to be transferred via the gearing. Out of lowering operation in connection with gearing and coupling clearances shock torques have to be transferred via the gearing. System design options:

Safety Coupling: A safety coupling located between motor and gearing is a means to limit the maximum gearing torques transferred by the gearing in case of a safety brake acting on the slow running axis. This especially applies for lifting operation. Aspects to be considered: Conflict between switch off at low load level and unfounded switch off, additional masses to the system, process of recommissioning of the safety coupling after burst, prevention of slack rope conditions, regulative and contractual requirements.

Freewheel Coupling: A freewheel coupling located between motor and gearing is a means to diminish the maximum gearing torques transferred by the gearing close to zero in case of a safety brake acting on the slow running axis. This especially applies for lowering operation [3]. Aspects to be considered: Additional masses to the system, regulative and contractual requirements.

Fast acting service brake: This system basically consists of a fast acting service brake. With a fast acting service brake both brakes come into action synchronous. As the motor masses are braked directly the torque transferred by the gearing is reduced significantly. Furthermore the two brakes realize the fastest braking for the whole system mass possible [4, 
$5,6,7,8]$. Aspects to be considered: Synchronization of brakes, regulative and contractual requirements.

\subsection{Snag Load}

A snag load occurs, when a load gets stuck during a lifting operation. The immediate fixation of the load causes high loads on the drive train especially at high speeds. System design options:

Hydraulic Protection System: This system is acting to the rope drive of the hoist. Either the rope end or a pulley is adapted to a hydraulic cylinder rod. With an arising overload an according hydraulic pressure in the cylinder is opening a pressure valve. The opened valve allows the cylinder rod to move out and the rope end or the pulley to move with the pending load. This gives a release to the rope drive and the whole drivetrain. A hydraulic protection system probably is combined with a fast acting safety brake, triggered by the hydraulic system condition. Aspects to be considered: Environmental protection, recommissioning after burst, prevention of slack rope conditions, regulative and contractual requirements.

Mechanical Protection System: This system basically consists of a safety clutch between motor and gearing. The occurring overload due to snag forces the clutch to open. This uncouples the dominant motor mass from the drivetrain. The mechanical protection system probably is combined with a fast acting safety brake, triggered by the mechanical protection system condition. The safety brake is enabled to brake down the drum very fast, as the system masses are quite reduced. The motor mass is uncoupled and the service brake disc may consist out of a material of low density. Aspects to be considered: Conflict between switch off at low load level and unfounded switch off, additional masses to the system, process of recommissioning of the safety coupling, after burst, prevention of slack rope conditions, regulative and contractual requirements.

Fast acting service brake: This system basically consists of a fast acting service brake. With a fast acting service brake both brakes come into action synchronous. As the motor masses are braked directly the torque transferred by the gearing is reduced significantly. Furthermore the two brakes realize the fastest braking for the whole system mass possible. $[4,5,6,7,8]$ Aspects to be considered: Synchronization of brakes, regulative and contractual requirements.

Sensoric Protection System: This system bases on measuring conditional changes at the load. By means of acceleration sensors and inclination sensors the corresponding physical conditions are measured and evaluated. As soon as the parameters indicate a snag case the braking process is triggered. A sensoric protection system probably is combined with a fast acting safety brake. Aspects to be considered: Prevention of unfounded bursts, regulative and contractual requirements.

\section{Outlook}

For the very basic load cases acceleration and pick up or drop off of load overloads are prevented by suitable design of the working cycle.

For certain load cases measures for preventing overloads to the hoist system are clear. The application of upper and lower limit switches is a quite common application to prevent slack rope, under ranging minimum rope windings on the rope drum and two blocking. This also applies for overload switches / frictional clutches to prevent overloads.

For other load cases, measures in some cases are applied. This applies for angle difference sensors comparing the gearing input and output rotation. Those sensors are just applied for non-serial winches in operations with higher safety requirements. 
For emergency stops and snag load cases different equipment options, beside the option of no additional equipment, are given. Whether an additional equipment and which additional equipment is of use, must be determined by thorough transient analysis of the dynamic system for relevant load cases. This requires the treatment of the whole system rather than single components. For experimental evaluation of the system behaviour as a result of the application of optional equipment an adequate testing rig s built up at ZAFT of THGA [12].

\section{References}

1. F. Schmeink, Dynamische Beanspruchung von Hubwerksgetrieben ... (Tagungsband der 22. Internationalen Kranfachtagung, Magdeburg 2014)

2. DIN EN 13001-2 Kransicherheit, Konstruktion allgemein, Teil 2: Lasteinwirkungen.

3. S. Vöth, STS-Crane-Hoist-Structure with Freewheel Coupling (to be published)

4. S. Vöth, M. Tyulenev, KuzSTU Bul., 1, 88-96 (2016)

5. S. Vöth, Hebezeuge und Fördermittel, 3 (2015)

6. S. Vöth, Hebezeuge und Fördermittel, 4 (2015)

7. S. Vöth, Hebezeuge und Fördermittel, 5 (2015)

8. A. Khoreshok, M. Tyulenev, S. Vöth, Conditions for minimum dynamic loading of multi brake hoists, 8th Russian-Chinese Symposium, Coal in the 21st century: Mining, Processing, Safety (Kuzbass State Technological University, Kemerovo, 2016)

9. RWTÜV-Schriftenreihe, Heft 8, Krane, Bemessung und Sicherheit, 1981

10. N. Schilling, G, Schneider, S. Vöth, Hebezeuge und Fördermittel, 7-8 (2017)

11. S. Vöth, Loading of hoist gearings due to fast running motors and additional brakes, (ITI, Dresden, 2016)

12. S. Vöth, E2S Web of Conferences, 15, 03007 (2017) 